ORIGINAL RESEARCH ARTICLE

\title{
High rates of Unintended Pregnancies among Young Women Sex Workers in Conflict-affected Northern Uganda: The Social Contexts of Brothels/Lodges and Substance Use
}

\author{
Putu Duff ${ }^{1,2}$, Godfrey Muzaaya ${ }^{3}$, Katherine Muldoon ${ }^{1}$, Sabina Dobrer ${ }^{1}$, Monika Akello , \\ Josephine Birungi ${ }^{3}$, and Kate Shannon ${ }^{1,2}$.
}

Gender and Sexual Health Initiative, British Columbia Centre for Excellence in HIV/AIDS, St. Paul's Hospital, 6081081 Burrard Street, Vancouver, BC, CANADA, V6Z 1Y6 ${ }^{1}$; Department of Medicine, University of British Columbia, St. Paul's Hospital, 608-1081 Burrard Street, Vancouver, BC, CANADA, V6Z 1Y6²; The AIDS Support Organization (TASO), Uganda ${ }^{3}$

*For Correspondence: Email: gshi@cfenet.ubc.ca; Phone: +1 604809459

\begin{abstract}
This study aimed to examine the correlates of unintended pregnancies among young women sex workers in conflict-affected northern Uganda. Data were drawn from the Gulu Sexual Health Study, a cross-sectional study of young women engaged in sex work. Bivariable and multivariable logistic regression was used to examine the correlates of ever having an unintended pregnancy. Among 400 sex workers (median age=20 years; IQR 19-25), 175 (43.8\%) reported at least one unintended pregnancy. In multivariable analysis, primarily servicing clients in lodges/brothels [Adjusted Odds Ratio (AOR=2.24; 95\% Confidence Interval: 1.03-4.84)], hormonal contraceptive usage [AOR=1.68; 95\%CI 1.11-2.59] and drug/alcohol use while working $[\mathrm{AOR}=1.64 ; 95 \% \mathrm{CI} 1.04-2.60]$ were positively correlated with previous unintended pregnancy. Given that unintended pregnancy is an indicator of unmet reproductive health need, these findings highlight a need for improved access to integrated reproductive health and HIV services, catered to sex workers' needs. Sex work-led strategies (e.g., peer outreach) should be considered, alongside structural strategies and education targeting brothel/lodge owners and managers. (Afr J Reprod Health 2017; 21[2]: 64-72).
\end{abstract}

Key words: sex work, reproductive health, HIV, Uganda, post-conflict

\section{Résumé}

Cette étude visait à examiner les corrélats des grossesses non désirées chez les femmes prostituées dans le nord de l'Ouganda touché par le conflit. Les données ont été tirées de l'étude sur la Santé Sexuelle de Gulu, une étude transversale des jeunes femmes engagées dans le travail du sexe. Une régression logistique bivariée et multivariable a été utilisée pour examiner les corrélats d'une grossesse non souhaitée. Parmi les 400 travailleuses du sexe (âge médian $=20$ ans, IQR 19-25), 175 (43,8\%) ont signalé au moins une grossesse non souhaitée. Dans l'analyse multivariable, principalement l'entretien des clients dans les lodges / bordels [Ratio de cotes ajusté (AOR = 2,24; Intervalle de confiance 95\%: 1,03-4,84)], l'utilisation de contraceptifs hormonaux [AOR = 1,68; IC 95\%: 1,11-2,59] et consommation de drogue / alcool pendant le travail [AOR = 1,64; 95\% IC 1.04-2.60] ont été positivement corrélés avec une grossesse non souhaitée antérieure. Étant donné que la grossesse non désirée est un indicateur des besoins de santé de la reproduction non satisfaits, ces résultats soulignent la nécessité d'améliorer l'accès aux services intégrés de santé de la reproduction et du traitement du VIH, répondant aux besoins des travailleurs du sexe. Les stratégies axées sur le travail sexuel (par exemple, la sensibilisation des pairs) devraient être considérées, parallèlement aux stratégies structurelles et à l'éducation ciblant les propriétaires et les gestionnaires de bordel / d'hôtel. (Afr J Reprod Health 2017; 21 [2]: 64-72).

Mots clés: travail du sexe, santé de la reproduction, VIH, Ouganda, après conflit

\section{Introduction}

In 2006, Northern Uganda emerged from over two decades of conflict between the Lord's Resistance Army (LRA) and the Ugandan government. This conflict devastated the region, with an estimated 20,000 boys and girls abducted by the LRA to serve as rebel soldiers and sex slaves. Much of the remaining population, an estimated 1.84 million people, were displaced to Internally Displaced 
People (IDP) camps ${ }^{1}$. As in other regions in Uganda, ongoing poverty and deprivation have contributed to the presence of an informal economic sex work sector ${ }^{2}$. This is despite the fact that sex work is criminalized in Uganda and sex workers face widespread harassment, discrimination and other human rights violations, including from the police and community members ${ }^{3}$.

People affected by conflict have heightened vulnerability to poor reproductive health outcomes, due to increased exposure to sexual violence, deprivation and related sexual risk patterns, as well as reduced access to sexual and reproductive health (SRH) services ${ }^{4}$. Despite reports suggesting a high unmet reproductive need in conflict-affected settings ${ }^{5}$, there remains limited peer-reviewed literature quantifying the need for reproductive health services in conflict and conflict affected settings ${ }^{6}$. Furthermore, despite the concomitant increase of transactional sex in conflict-affected regions ${ }^{2,7}$, there remains a limited understanding of sex workers' reproductive health needs and outcomes ${ }^{8}$. This is an important gap, given that sex workers globally are disproportionately affected by reproductive health inequities $^{9,12}$. The intersecting sexual and reproductive risks among sex workers in conflict affected northern Uganda are particularly concerning, given recent estimates documenting a HIV prevalence of $8.51 \%$ among the general population, and $37.2 \%$ among sex workers ${ }^{13}$.

While several studies in sub-Saharan Africa have documented high levels of pregnancy and parenting among sex workers ${ }^{14,15}$, data on pregnancy intentions (both prospectively or retrospectively) among sex workers are scarce ${ }^{16}$. This is especially true of sex workers in the Ugandan context, where sex work criminalization has hindered collection of data surrounding sex workers' sexual and reproductive health ${ }^{17}$. Our literature review located no studies examining unintended pregnancies among sex workers in conflict-affected settings, however a handful of studies from other sub-Saharan African countries suggest unintended pregnancies may be a common occurrence among sex workers. For example, $86 \%$ of sex workers in Kenya reported at least one previous abortion, with $50 \%$ reporting more than one $^{14}$. In Madagascar, 52\% of sex workers reported prior unwanted pregnancy, and $45 \%$ had least one abortion ${ }^{15}$. Eighty-six percent indicated that preventing future pregnancy was moderately to very important. In this context, reduced ability to negotiate condom use and limited knowledge of contraceptive was associated with unwanted pregnancy ${ }^{15}$. Other studies have linked alcohol or illicit drug use to unwanted pregnancy ${ }^{18}$, including a study among sex workers in Northern Ethiopia ${ }^{19}$, and suggest that sex workers who use substances may be at more risk of unprotected $\operatorname{sex}^{19}$.

In light of the paucity of literature pertaining to unintended pregnancy of marginalized populations, including sex workers, in conflict settings, this study aimed to examine the correlates of unintended pregnancy among young women sex workers in conflict- affected northern Uganda.

\section{Methods}

\section{Design and sampling}

This analysis drew on cross-sectional data from the Gulu Sexual Health Study, a community-based study on HIV prevention, treatment and care among cis-gendered sex workers. Eligibility criteria included: being 14 years or older, having exchanged sex for money or other resources such as food, clothing or shelter within the last month. Ethical approval was obtained to include participants 14-17 years who were living independently (without guardians) as they were considered mature and emancipated minors. An adapted consenting procedure was used for these participants, as well as special safeguards to assess their ability to provide informed consent. In partnership with TASO Gulu (The AIDS Support Organization) and other community-organizations (including youth-, sex worker-, women- and health service- organizations), data were collected between May 2011 and January 2012.

Participants were recruited using peer/sex worker-led (current and former sex workers) outreach to bars and hotels. Community-led outreach to former internally displaced persons (IDP) camps (i.e., Pabbo, Bobi, Awach, Labongogali), in partnership with the TASO Gulu clinic were also used to recruit participants. Following informed consent, an interviewer- 
administered questionnaire was conducted in the local language (Luo) by research assistants who were of the Acholi ethnic group. The Acholi people are the most common ethnic group in Northern Uganda and speak the Luo language. The Acholi research assistants were trained for data collection as well as voluntary HIV counseling and testing. The survey instrument elicited a wide range of information, including: sociodemographics, sex work histories, substance use, current work environments, experiences of client-, and intimate partner-, and war related-violence. As well, data on sexual and reproductive health, HIV prevention and care were also collected. The questionnaire was validated and approved by sex workers and sex worker and community groups prior to data collection. Trained research assistants also offered voluntary HIV counseling and testing. The study received ethical approval from the University of British Columbia's Behavioural Research Ethics Board, TASO Research and Ethics Committee, with protocol registered at the Ugandan National Council for Science and Technology.

Descriptive analysis for this sample included the calculation of frequencies and proportions for categorical variables, and mean, medians and interquartile ranges (IQR) for continuous data. Bivariable analysis was conducted to determine the independent associations with previous unintended pregnancy, defined as ever having one or more unintended pregnancies (versus intended pregnancies or no pregnancies), using Pearson's chi-squared tests for binary categorical variables and Wilcoxon ranksum test for continuous variables. Fisher's exact test was used when cell sizes were insufficient $(<5)$. To measure the strength of association between categorical variables, Odds Ratios (ORs) with 95\% Confidence Intervals (CIs) were provided. A priori known confounders and variables with $p$-values of $<0.10$ were considered for inclusion in the multivariable model, and a backwards selection approach using Akaike's Information Criteron (AIC) was used to arrive at the final model. Age and education were forced into the multivariable model based on their $a$ priori knowledge as a well-established correlate of unintended pregnancy. Variables were considered significant if they maintained $p$-values $<0.05$ after adjusting for covariates in the multivariable model. The final model was tested for multi-collinearity.

\section{Results}

Of the total sample of 400 sex workers, the median age was 20 years (IQR 19-25), 175 (43.8\%) reported at least one unintended pregnancy and most participants $(99.2 \%)$ were single or widowed. The majority of participants were from the Luo or Acholi tribes (92.3\%), followed by Lango tribe (2.8\%). Over one-third (33.8\%) of the participants were living with HIV, with $46.8 \%$ having ever used modern contraceptives (e.g., birth control pill, hormonal contraceptives). Almost one-third $(30.8 \%)$ had been previously abducted by the Lord's Resistance Army (LRA) (30.8\%) and $66.5 \%$ had lived in IDP camps (See Table 1).

In bivariable analysis, primarily servicing clients in brothels/lodges (OR 2.35; 95\%CI: 1.114.97), ever use of modern contraceptives for family planning (OR 1.79; 95\%CI: 1.20 - 2.67) and having used alcohol/drugs on a date (OR 1.73; 1.11-2.69) were significantly associated with unintended pregnancy at $p<0.05$. In multivariable analyses, ever servicing clients in a brothel or lodge (AOR 2.24; 95\% CI:1.03-4.84), having ever used modern contraception for pregnancy prevention (AOR=1.70; 95\%CI: 1.11-2.59) and having used alcohol/drugs while on a date (AOR 1.64 (95\% CI: 1.05-2.60) were positively associated with a previous unintended pregnancy. Bivariable and multivariable results are presented in Table 2.

\section{Discussion}

This current study documented a high level of unintended pregnancy among sex workers in conflict affected northern Uganda, compared the prevalence of unintended pregnancies in the general Ugandan population $(38 \%)^{20}$. The prevalence of previous unintended pregnancy of $43.8 \%$ is particularly high considering the young age of the sample. While studies reporting unintended pregnancy rates in conflict-affected sub-Saharan Africa are limited, similarly high levels of unwanted pregnancy have been reported among a (slightly older) cohort sex workers in 
Table 1: Sample Characteristics Of 400 Sex Workers in Gulu, Northern Uganda Who Reported Ever Having/Not Having an Unintended Pregnancy, with Two Sided p-Values

\begin{tabular}{|c|c|c|c|c|}
\hline Characteristic & $\begin{array}{l}\text { Total } \\
400(100 \%)\end{array}$ & $\begin{array}{l}\text { Previous unintended } \\
\text { pregnancy } \\
\mathbf{1 7 5}(\mathbf{4 3 . 8 \% )}\end{array}$ & $\begin{array}{l}\text { No unintended } \\
\text { pregnancy } \\
\mathbf{2 2 5}(\mathbf{5 6 . 3 \%})\end{array}$ & $p$ - value \\
\hline Age median (Interquartile range) & & $22.0(20-26)$ & $20.0(19-25)$ & 0.026 \\
\hline \multicolumn{5}{|l|}{ Tribe } \\
\hline Langi & $11(2.8)$ & $6(3.4)$ & $5(2.2)$ & 0.464 \\
\hline Acholi & $369(92.5)$ & $160(91.4)$ & $209(92.9)$ & REF \\
\hline Other & $19(4.8)$ & $8(4.6)$ & $11(4.9)$ & 0.914 \\
\hline \multicolumn{5}{|l|}{ Education } \\
\hline Completed secondary education & $8(2.0)$ & $4(2.29)$ & $4(1.8)$ & 0.527 \\
\hline Completed primary & $137(34.3)$ & $72(41.1)$ & $65(29.9)$ & 0.009 \\
\hline Less than primary & $255(63.7)$ & $99(56.6)$ & $156(69.3)$ & REF \\
\hline \multicolumn{5}{|l|}{ HIV Status } \\
\hline $\mathrm{HIV}+$ & $135(33.8)$ & $58(33.1)$ & $77(34.2)$ & 0.821 \\
\hline HIV- & $265(66.2)$ & $117(66.9)$ & $148(65.8)$ & REF \\
\hline \multicolumn{5}{|l|}{ Marital status } \\
\hline Married/Living together & $3(0.8)$ & $3(1.7)$ & $0(0.0)$ & 0.083 \\
\hline Single/widowed & $397(99.2)$ & $172(98.3)$ & $225(100.0)$ & REF \\
\hline \multicolumn{5}{|l|}{$\begin{array}{l}\text { Ever used male condom for family } \\
\text { planning }\end{array}$} \\
\hline yes & $358(89.5)$ & $157(89.7)$ & $201(89.3)$ & 0.901 \\
\hline & $42(10.5)$ & $18(10.3)$ & $24(10.7)$ & REF \\
\hline \multicolumn{5}{|l|}{$\begin{array}{l}\text { Ever used modern contraceptives for } \\
\text { family planning }\end{array}$} \\
\hline yes & $187(46.8)$ & $96(54.9)$ & $91(40.4)$ & 0.004 \\
\hline no & $213(53.3)$ & $79(45.1)$ & $134(59.6)$ & REF \\
\hline \multicolumn{5}{|l|}{ Lived in an IDP camp } \\
\hline yes & $266(66.5)$ & $117(66.9)$ & $149(66.2)$ & 0.893 \\
\hline no & $134(33.5)$ & $58(33.1)$ & $76(33.8)$ & $\mathrm{REF}$ \\
\hline \multicolumn{5}{|l|}{ Abducted by the Lord's Resistance Army } \\
\hline yes & $123(31.1)$ & $59(33.7)$ & $64(28.4)$ & 0.262 \\
\hline no & $272(68.9)$ & $114(65.1)$ & $158(70.2)$ & REF \\
\hline \multicolumn{5}{|l|}{ Ever serviced clients in brothels/lodges } \\
\hline yes & $362(90.5)$ & $165(94.3)$ & $197(87.6)$ & 0.019 \\
\hline no & $38(9.5)$ & $10(5.7)$ & $28(12.4)$ & REF \\
\hline \multicolumn{5}{|l|}{ Ever used alcohol/drugs while on a date } \\
\hline yes & $274(68.5)$ & $132(75.4)$ & $142(63.1)$ & $<0.001$ \\
\hline no & $126(31.5)$ & $43(24.6)$ & $83(36.9)$ & REF \\
\hline * IQR: Interquartile range & & & & \\
\hline
\end{tabular}

Swaziland $(50.2 \%)^{21}$. As our study examined ever unintended pregnancy, it is unclear whether these unintended pregnancies occurred amidst the LRA conflict or post-conflict. There are evidence from conflict-affected Liberia that documented exchanges of sex for protection during conflict ${ }^{7}$. The power imbalances established within such transactions have been described to reduce women's ability to negotiate and use condoms ${ }^{7}$, and may contribute to unintended pregnancies both during and after conflict.

A growing body of research has highlighted the influential, yet heterogeneous role of sex work venue features on HIV/pregnancy prevention $^{22}$, however empirical evidence from sub-Saharan African settings remain scarce ${ }^{22}$. Epidemiological studies have shown a number of practices in venues can promote condom 
Table 2: Correlates of Unintended Pregnancies among 400 Sex Workers in Gulu, Northern Uganda, with Bivariable (OR) and Multivariable Odds Ratios (AOR), and 95\% Confidence Intervals (95\% CIs)

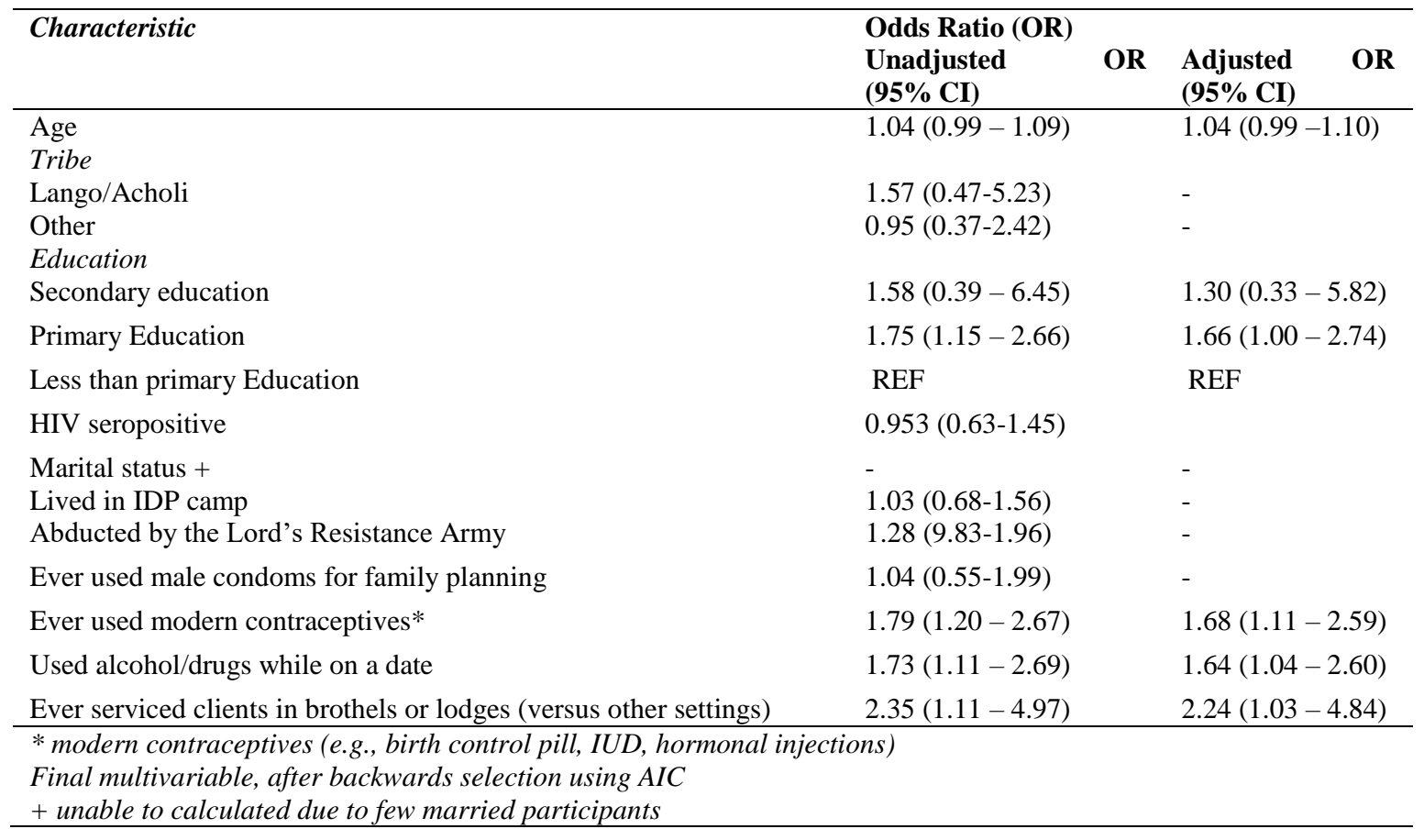

negotiation, such as onsite access to condoms, managers who are supportive of HIV prevention, and having managers, peers or other third parties that can intervene if clients become violent ${ }^{23,25}$. A Canadian study found that having a combination of such supports in sex work venues was linked to increased use of contraception for pregnancy prevention $^{26}$. In this study in northern Uganda, the association between working in a brothel/lodge may reflect a lack of supportive physical or social features within sex workers' venues. A study among sex workers who worked along the TransAfrican Highway in Uganda and Kenya found that having access to condoms on-site increased condom use by clients ${ }^{27}$. The study suggests that Ugandan sex workers have lower condom use due to less access to condoms in their workplaces compared to Kenyan sex workers. Specifically, in Uganda, sex workers have less access to peer outreach services that distribute condoms, less condom availability in the workplace, and less HIV/STI education ${ }^{27}$. Widespread condom shortages have also been reported in Gulu and across northern Uganda by community-based organizations (CBOs) and AIDS service organizations during the post-conflict phase, with community concerns that sex workers bear the brunt of this public health crisis $^{28}$. Qualitative evidence from sub-Saharan Africa has also shown that the criminalization of sex work has resulted in harassment and arrest, for outreach workers found distributing condoms ${ }^{29}$. Sex workers in brothels and lodges are the least visible to peer and CBO outreach efforts (compared to bar and street-based sex workers) suggesting a need to scale-up efforts for sex worker-led services for more hidden lodge and brothel-based sex workers. Extending qualitative evidence elsewhere, our findings highlight a need for further examination into the role that social, policy and physical contexts play in shaping condom negotiation and use among sex workers in brothels and lodges; this includes potential client and manager incentives and coercion for non-condom use, as noted in Uganda $^{30}$ and Nigeria ${ }^{31}$. In other settings globally, social cohesion and community empowerment (e.g., sex worker collectives, programming and services led and/or run by sex workers) among brothel-based sex workers has been found to promote safer industry norms ${ }^{32,33}$.

While just under half $(46.7 \%)$ of participants indicated ever use of modern 
contraceptives (i.e., birth control pill, intrauterine devices, hormonal injections), the positive association between modern contraceptives and unintended pregnancy may be explained by poor/interrupted access and/or ineffective use of these contraceptives. Previous work from this cohort revealed poor or no access to contraceptives, with $50 \%$ experiencing barriers to accessing condoms or contraceptives ${ }^{8}$. Indeed, ineffective use, frequent discontinuation and method switching have been reported among sex workers in Madagascar and linked to unintended pregnancy ${ }^{15}$. Another possible explanation for the positive association between modern contraception and unintended pregnancy is that sex workers who ever had an unintended pregnancy began taking modern contraceptives to prevent future pregnancies $^{8}$.

The strong link between alcohol and drug use and reduced ability to negotiate for and use condoms has also been empirically demonstrated in Low- and middle-income countries (LMICs) including the Philippines and China ${ }^{34,35}$. Qualitative narratives from Ugandan sex workers illustrate how clients often take advantage of drunk sex workers by coercing them into unprotected $\operatorname{sex}^{30}$. In Kampala, sex workers' alcohol use has been found to be independently associated with HIV infection ${ }^{36},{ }^{37}$ and violence ${ }^{38}$, similar associations have been consistently documented across settings in Sub-Saharan Africa $^{39}$. In Mombasa, Kenya, alcohol use in sex work transactions was linked to higher rates of sexual violence, which increased HIV acquisition risk for sex workers ${ }^{27}$.

Of concern, alongside the high rates of unintended pregnancy (43\%), our study demonstrated a high burden of HIV among sex workers'; a rate considerably higher compared to the general population in northern Uganda (37.2\% versus $8.5 \%)^{13}$. The co-occurrence of both pregnancy and HIV highlight the potential for mother-to-child transmission of HIV (among sex workers who decide to keep their children), and points to a need for improved access to sex worker-tailored and sex worker-friendly Prevention of Mother to Child Transmission (PMTCT) Services integrated into existing HIV services. Qualitative research from Tanzania sheds light on some of the barriers faced by pregnant sex workers in accessing antenatal services, including stigma related to sex work and being pregnant out of wedlock ${ }^{40}$.

Taken together, these findings indicate a high level of unmet reproductive need among women sex workers in conflict-affected Uganda. There is a need for improved access to sex workerfriendly and integrated sex worker-tailored reproductive health services (including Prevention of Mother-to-Child Transmission services) especially for sex workers working in brothels and lodges. Previous research from Gulu found that access to integrated HIV services was independently associated with dual contraceptive use for pregnancy prevention, suggesting that increased access to integrated HIV/SRH services could help mitigate sex worker s' reproductive health inequities ${ }^{8}$. Sex worker -tailored and sex worker -led services that include peer-led and outreach components are pivotal to improving access to HIV/SRH services ${ }^{41}$. This is particularly important given sex workers' accounts of displacement and avoidance of health services due to police enforcement ${ }^{42}$, stigma $^{40}$, and poor treatment by health care staff ${ }^{43,44}$.

Additionally, to develop workplace models that better support sex workers' sexual and reproductive health, future research needs to better elucidate the role of sex work venues on HIV and pregnancy prevention. This includes implementing and evaluating strategies to reach and educate brothel/lodge owners and managers on HIV/pregnancy prevention. The current criminalization and punitive approaches to sex work have a strong potential to undermine efforts for structural interventions that promote sex workers' health and human rights, such as educating managers and increasing access to HIV and violence prevention services or venue features ${ }^{27,28}$. Qualitative narratives by sex workers across East Africa have shown denial of health services to be a major concern and the production of a criminalized and stigmatized environment ${ }^{45}$. Harm reduction interventions, such as those in the Philippines that work with managers and sex workers to reduce alcohol use at work and protect sex workers from client violence should be considered in Gulu ${ }^{25}$. 


\section{Limitations}

Our analysis contains a number of notable limitations. As this study used a cross-sectional design, temporality cannot be inferred. This limitation extends to our primary outcome, previous unintended pregnancy, negating our ability to estimate correlates of pregnancy incidence. Given the criminalized and clandestine nature of sex work in Uganda, the findings from this sample may not be generalizable to sex workers from all settings. Furthermore, while community-based approaches to recruitment were employed, our sampling frame may still not capture some of the more marginalized sex workers who may be at increased risk of poor HIV/SRH service access and unintended pregnancy. Finally, the variables in this analysis were self-report and thus may be subject to social desirability bias. Despite the aforementioned limitations, high levels of unintended pregnancies were reported among this sample, highlighting the tremendous reproductive health gap present in conflict-affected Uganda.

\section{Conclusion}

To conclude, this study underscores a significant reproductive health gap among sex workers in conflict-affected Uganda, signaling a need to improve access to integrated reproductive health and HIV services, including family planning (including female-controlled contraceptives) and PMTCT services, catered to the sex worker population. Sex work-led strategies, including peer outreach, education (for sex workers and owners/managers), and harm reduction should be considered, especially for sex workers working in brothel/lodge-based settings.

\section{Acknowledgments}

We thank all those who contributed their time and expertise, particularly participants, outreach teams, TASO Gulu community advisory board and humanitarian/refugee, youth, women, and sex work partner agencies. We wish to acknowledge Godfrey Muzaaya, Esther Achan, Josephine Birguni, Monika Akello, Miriam, Jacky Ayat,
Beatrice Baraka, Bibian Achan, Grace Lakot, Winnie Amunu, Andrew Mijumbi Ojok. This research was supported by a CIHR Team Grant (TVG-115616). PD is supported by CIHR and Michael Smith Foundation for Health Research (MSFHR) Postdoctoral Award. KS is supported by a Canada Research Chair in Global Sexual Health and HIV/AIDS and Michael Smith Foundation for Health Research.

\section{References}

1. United Nations High Commissioner for Refugees. UNHCR closes chapter on Uganda's internally displaced people. 2012. Available at http://www.unhcr.org/news/briefing/2012/1/4f06e2a 79/unhcr-closes-chapter-ugandas-internallydisplaced-people.html.

2. Muhwezi W, Kinyanda E, Mungherera M, Onyango P, Ngabirano E, Muron J, Kagugube J and Kajungu R. Vulnerability to high risk sexual behaviour (HRSB) following exposure to war trauma as seen in postconflict communities in eastern uganda: a qualitative study. Confl Health 2011;5(1):22. Doi: 10.1186/1752-1505-5-22.

3. Muldoon KA, Akello M, Muzaaya G, Simo A, Shoveller J and Shannon K. Policing the epidemic: High burden of workplace violence among female sex workers in conflict-affected northern Uganda. Glob Public Health 2015:1-14. Doi: 10.1080/17441692.2015.1091489.

4. Chi PC, Bulage P, Urdal H and Sundby J. Perceptions of the effects of armed conflict on maternal and reproductive health services and outcomes in Burundi and Northern Uganda: a qualitative study. BMC Int Health Hum Rights 2015;15(1):1-15. Doi: 10.1186/s12914-015-0045-z.

5. Bosmans M, Cikuru M, Claeys $\mathrm{P}$ and Temmerman $\mathrm{M}$. Where have all the condoms gone in adolescent programmes in the Democratic Republic of Congo. Reprod Health Matters 2006;14:80-8.

6. Dickinson FM, Pyone T and van den Broek N. Experiences from the field: maternal, reproductive and child health data collection in humanitarian and emergency situations. Int Health 2016;8(2):83-8. Doi: 10.1093/inthealth/ihv045.

7. Atwood K, Kennedy S, Barbu E, Nagbe W, Seekey W, Sirleaf P, Perry O, Martin RB and Sosu F. Transactional sex among youth in post conflict Liberia. J Heal Popul Nutr 2011;29(2):113-22.

8. Erickson M, Goldenberg S, Akello M, Ajok M, Nguyen P, Muldoon KA, Muzaaya $G$ and Shannon K. Structural determinants of dual contraceptive use among female sex workers in conflictaffected Gulu, northern Uganda. Under Rev IJOG 2014.

9. Overs $\mathrm{C}$ and Hawkins K. Can rights stop the wrongs? 
Exploring the connections between framings of sex workers' rights and sexual and reproductive health. BMC Int Health Hum Rights 2011;11 Suppl 3(Suppl 3):S6. Doi: 10.1186/1472-698X-11-S3-S6.

10. Decker MR, Yam EA, Wirtz AL, Baral SD, Peryshkina A, Mogilnyi $\mathrm{V}$ and Beyrer C. Induced abortion, contraceptive use, and dual protection among female sex workers in Moscow, Russia. Int $J$ Gynecol Obstet 2013;120(1):27-31. Doi: 10.1016/j.ijgo.2012.07.026.

11. Becker $\mathrm{M}$, Ramanaik S, Halli S, Blanchard JF, Raghavendra T, Bhattacharjee $\mathrm{P}$, Moses $\mathrm{S}$ and Mishra S. The Intersection between Sex Work and Reproductive Health in Northern Karnataka, India: Identifying Gaps and Opportunities in the Context of HIV Prevention. AIDS Res Treat 2012;2012:842576. Doi: 10.1155/2012/842576.

12. Chacham AS, Diniz SG, Maia MB, Galati AF and Mirim LA. Sexual and reproductive health needs of sex workers: two feminist projects in Brazil. Reprod Heal Matters 2007;15(29):108-18. Doi: S0968-8080(07)29292-4 [pii]10.1016/S09688080(07)29292-4 [doi].

13. Baral S, Beyrer C, Muessig K, Poteat T, Wirtz AL, Decker MR, Sherman SG and Kerrigan D. Burden of HIV among female sex workers in low-income and middle-income countries: A systematic review and meta-analysis. Lancet Infect Dis 2012:538-49.

14. Elmore-Meegan M, Conroy RM and Agala CB. Sex Workers in Kenya, Numbers of Clients and Associated Risks: An Exploratory Survey. Reprod Health Matters 2004;12(23):50-7.

15. Feldblum PJ, Nasution MD, Hoke TH, Van Damme K, Turner AN, Gmach R, Wong EL and Behets F. Pregnancy among sex workers participating in a condom intervention trial highlights the need for dual protection. Contraception 2007;76(2):105-10.

16. Schwartz S, Papworth E, Thiam-Niangoin M, Abo K, Drame F, Diouf D, Bamba A, Ezouatchi R, Tety J, Gover $\mathrm{E}$ and Baral S. An urgent need for integration of family planning services into HIV care: the high burden of unplanned pregnancy, termination of pregnancy, and limited contraception use among female sex workers in Côte d'Ivoire. $J$ Acquir Immune Defic Syndr2015;68(Suppl 2):S91-8.

17. Patel S, Schechter MT, Sewankambo NK, Atim S, Kiwanuka N and Spittal PM. Lost in transition: HIV prevalence and correlates of infection among young people living in post-emergency phase transit camps in Gulu District, Northern Uganda. PLoS One 2014;9(2):e89786.

Doi:

10.1371/journal.pone.0089786.

18. Zhang X, Kennedy E, Temmerman M, Li Y, Zhang W and Luchters S. High rates of abortion and low levels of contraceptive use among adolescent female sex workers in Kunming, China: A cross-sectional analysis. Eur J Contracept Reprod Heal Care 2014;19(5):368-78

Doi: 10.3109/13625187.2014.927421

19. Weldegebreal R, Melaku YA, Alemayehu M and
Gebrehiwot TG. Unintended pregnancy among female sex workers in Mekelle city, northern Ethiopia: a cross-sectional study. BMC Public Health 2015;15:40. Doi: 10.1186/s12889-015-13665.

20. Singh S. Unintended Pregnancy and Induced Abortion in Uganda: Causes and Consequences. New York: 2006.

21. Yam EA, Mnisi Z, Sithole B, Kennedy C, Kerrigan D, Tsui A and Baral S. Association Between Condom Use and Use of Other Contraceptive Methods Among Female Sex Workers in Swaziland: A Relationship-Level Analysis of Condom and Contraceptive Use. Sex Transm Dis 2013;40(5):406-12.

22. Shannon K, Strathdee SA, Goldenberg SM, Duff P, Mwangi P, Rusakova M, Reza-Paul S, Lau J, Deering K, Pickles MR and Boily MC. Global epidemiology of HIV among female sex workers: influence of structural determinants. Lancet 2014;6736(14). Doi: $\quad$ 10.1016/S01406736(14)60931-4.

23. Krüsi A, Chettiar J, Ridgway A, Abbott J, Strathdee SA and Shannon K. Negotiating safety and sexual risk reduction with clients in unsanctioned safer indoor sex work environments: a qualitative study. $A m J$ Public Health 2012;102(6):1154-9. Doi: 10.2105/AJPH.2011.300638.

24. Kerrigan D, Moreno L, Rosario S, Gomez B, Jerez H, Barrington $\mathrm{C}$, Weiss $\mathrm{E}$ and Sweat $\mathrm{M}$. Environmental-structural interventions to reduce HIV/STI risk among female sex workers in the Dominican Republic. Am $J$ Public Health 2006;96(1):120-5.

25. Urada LA, Morisky DE, Hernandez LI and Strathdee SA. Social and structural factors associated with consistent condom use among female entertainment workers trading sex in the Philippines. AIDS Behav 2013;17(2):523-35. Doi: 10.1007/s10461-0110113-x.

26. Duff P, Shoveller J, Dobrer S, Ogilvie G, Montaner J, Chettiar J and Shannon K. The relationship between social, policy and physical venue features and social cohesion on condom use for pregnancy prevention among sex workers: a safer indoor work environment scale. $J$ Epidemiol Community Heal 2015:1-7. Doi: 10.1136/jech2014-204427.

27. Morris CN, Morris SR and Ferguson AG. Sexual behavior of female sex workers and access to condoms in Kenya and uganda on the trans-Africa highway. AIDS Behav 2009;13(5):860-5. Doi: 10.1007/s10461-008-9431-z.

28. IRIN PlusNews. Uganda: Desperately seeking condoms in the north. Reproductive Health Matters. Available at http://www.rhmjournal.org.uk/news.php?newsID=6 922011.

29. Open Society Foundations. Criminalizing Condoms: How Policing Practices Put Sex Workers And HIV Services at Risk in Kenya, Namibia, Russia, South 
Africa, The United States, and Zimbabwe. 2012. Available https://www.opensocietyfoundations.org/reports/cri minalizing-condoms.

30. Mbonye M, Nakamanya S, Nalukenge W, King R, Vandepitte $\mathbf{J}$ and Seeley J. 'It is like a tomato stall where someone can pick what he likes': structure and practices of female sex work in Kampala, Uganda. BMC Public Health 2013;13:741. Doi: 10.1186/1471-2458-13-741.

31. Muñoz FA, Pollini RA, Zúñiga ML, Strathdee SA, Lozada R, Martínez GA, Valles-Medina AM, Sirotin N and Patterson TL. Condom Access : Associations with Consistent Condom Use among Female Sex Workers in Two Northern Border Cities of Mexico 2010;22(5):455-65.

32. Kerrigan D, Telles P, Torres H, Overs C and Castle C. Community development and HIV/STI-related vulnerability among female sex workers in Rio de Janeiro, Brazil. Health Educ Res 2008;23(1):13745. Doi: 10.1093/her/cym011.

33. Lippman SA, Donini A, Díaz J, Chinaglia M, Reingold A and Kerrigan D. Social-environmental factors and protective sexual behavior among sex workers: the Encontros intervention in Brazil. Am $J$ Public Health 2010;100 Suppl :S216-23. Doi: 10.2105/AJPH.2008.147462.

34. Urada LA, Morisky DE, Pimentel-Simbulan N, Silverman JG and Strathdee SA. Condom negotiations among female sex workers in the Philippines: environmental influences. PLoS One 2012;7(3):e33282. Doi: 10.1371/journal.pone.0033282.

35. Zhang C, Li X, Stanton B, Hong Y, Chen Y, Shan Q, Liu $\mathrm{W}$ and Zhou Y. Alcohol use and client-perpetrated sexual violence against female sex workers in China. Psychol Heal Med 2013;18(3):330-42. Doi: 10.1080/13548506.2012.712705.

36. Vandepitte J, Bukenya J, Weiss HA, Nakubulwa S, Francis SC, Hughes P, Hayes R and Grosskurth H. HIV and Other Sexually Transmitted Infections in a Cohort of Women Involved in High-Risk Sexual Behavior in Kampala, Uganda. Sex Transm Dis 2011;38(4):1.
10.1097/OLQ.0b013e3182099545.

37. Bukenya J, Vandepitte J, Kwikiriza M, Weiss HA, Hayes $\mathrm{R}$ and Grosskurth H. Condom use among female sex workers in Uganda. AIDS Care 2013;25(6):767-74. Doi: 10.1080/09540121.2012.748863.

38. Schwitters A, Swaminathan M, Serwadda D, Muyonga M, Shiraishi RW, Benech I, Mital S, Bosa R, Lubwama $\mathrm{G}$ and Hladik W. Prevalence of rape and clientinitiated gender-based violence among female sex workers: Kampala, Uganda, 2012. AIDS Behav 2015;19(S1):S68-76.

39. Fisher JC, Bang $\mathrm{H}$ and Kapiga S. The Association Between HIV Infection and Alcohol Use: A Systematic Review and Meta-Analysis of African Studies. Sex Transm Dis 2007;34(11):856-63.

40. Beckham SW, Shembilu CR, Brahmbhatt H, Winch PJ, Beyrer C and Kerrigan DL. Female Sex Workers' Experiences with Intended Pregnancy and Antenatal Care Services in Southern Tanzania. Stud Fam Plann 2015; 46(1):55-71.

41. Stadler J and Delany S. The "healthy brothel": the context of clinical services for sex workers in Hillbrow, South Africa. Cult Health Sex 2006;8(5):451-64. Doi: 10.1080/13691050600872107.

42. Shannon K, Rusch M, Shoveller J, Alexson D, Gibson K and Tyndall MW. Mapping violence and policing as an environmental-structural barrier to health service and syringe availability among substance-using women in street-level sex work. Int J Drug Policy 2008;19(2):140-7.

43. Lazarus L, Deering KN, Nabess R, Gibson K, Tyndall MW and Shannon K. Occupational stigma as a primary barrier to health care for street-based sex workers in Canada. Heal (San Fr 2011;00(0):1-12.

44. Duff P, Shoveller J, Chettiar J, Feng CX, Nicoletti R and Shannon K. Sex Work and Motherhood: Social and Structural Barriers to Health and Social Services for Pregnant and Parenting Street and Off-Street Sex Workers. Health Care Women Int 2014;Epub ahead.

45. Scorgie F, Vasey K, Harper E, Richter M, Nare P, Maseko $S$ and Chersich MF. Human rights abuses and collective resilience among sex workers in four African countries: a qualitative study. Global Health 2013;9(1):33. Doi: 10.1186/1744-8603-9-33. 